\title{
Audiologic Patterns of Otic Capsule Preserving Temporal Bone Fracture: Effects of the Affected Subsites
}

\author{
So Young Kim · Yoon Joong Kim · Young Ho Kim · Min-Hyun Park \\ Department of Otorhinolaryngology, Boramae Medical Center, Seoul Metropolitan Government-Seoul National University, Seoul, Korea
}

Objectives. This study was aimed to assess the relationship between the type of temporal bone area involved and conductive hearing loss.

Methods. We enrolled 97 patients who visited the otolaryngology clinics of Seoul National University Hospital or Boramae Medical Center, Seoul Metropolitan Government-Seoul National University with temporal bone fracture between January 2004 and January 2014. Audiometric parameters, including initial and improved air-bone (AB) conduction gap values, were reviewed in accordance with the temporal bone computed tomography (external auditory canal [EAC], middle ear [ME], mastoid [M], and ossicle [O]).

Results. Patients with ossicular chain involvement exhibited a larger $\mathrm{AB}$ gap compared to those with no ossicular chain involvement at 250,1,000,2,000, and 4,000 Hz. Among the groups without ossicular chain involvement, the initial $\mathrm{AB}$ gap was largest in patients with $\mathrm{EAC}+\mathrm{ME}+\mathrm{M}$ involvement, followed by the $\mathrm{ME}+\mathrm{M}$ and $\mathrm{M}$-only involvement groups. The greatest improvement in the $\mathrm{AB}$ gap was observed in the $\mathrm{EAC}+\mathrm{ME}+\mathrm{M}$ group followed by the $\mathrm{ME}+\mathrm{M}$ and $\mathrm{M}$-only groups, irrespective of ossicular chain involvement. Improvements in AB gap values were smallest at 2,000 Hz.

Conclusion. Conductive hearing loss pattern differed according to the temporal bone area involved. Therefore, areas such as the hematoma and hemotympanum, as well as the fracture line of the temporal bone area, must be evaluated to predict audiologic patterns with otic capsule preserving temporal bone fracture.

Keywords. Temporal Bone; Fracture, Bone; Sensorineural Hearing Loss; Conductive Hearing Loss; Ear Ossicles

\section{INTRODUCTION}

Temporal bone fracture has been evaluated by several classification systems [1]. The traditional temporal bone fracture classification system was devised in accordance with the fracture direction in relation to the petrous ridge, with fractures classified as transverse, longitudinal, or mixed [2]. This classification system is based on a series of experiments conducted on cadaveric tem-

\footnotetext{
- Received July 9, 2015

Revised August 18, 2015

Accepted September 2, 2015

- Corresponding author: Min-Hyun Park

Department of Otorhinolaryngology, Boramae Medical Center, Seoul

Metropolitan Government-Seoul National University, 20 Boramae-ro 5-gil,

Dongjak-gu, Seoul 07061, Korea

Tel: +82-2-870-2443, Fax: +82-2-870-2459

E-mail: drpark@snu.ac.kr
}

poral bone demonstrating that fractures of the temporal bone occur along lines of anatomical weakness, such as suture lines or weak, aerated portions of the temporal bone [3]. However, predicting complications that arise from temporal bone fractures is of sufficient clinical importance to warrant more precise classification than simply describing anatomical and orientation features.

Therefore, new classification systems for temporal bone fractures have been developed. For example, there are classification systems based on the involvement of the petrous bone and otic capsule [4,5], which emphasize the structures involved rather than simply the orientation of the fracture. Otic capsule-violating fractures are associated with a higher incidence of both intracranial and otologic complications, such as facial nerve injury and sensorineural hearing loss (SNHL), compared to otic capsule-preserving fractures $[4,6,7]$. Furthermore, petrous bone

Copyright (C) 2016 by Korean Society of Otorhinolaryngology-Head and Neck Surgery.

This is an open-access article distributed under the terms of the Creative Commons Attribution Non-Commercial License (http://creativecommons.org/licenses/by-nc/4.0)

which permits unrestricted non-commercial use, distribution, and reproduction in any medium, provided the original work is properly cited. 
fractures are associated with SNHL and vertigo [6]. However, no classification system has demonstrated definitive superiority with respect to predicting the likelihood of any other clinical injury, particularly conductive hearing loss (CHL) [8,9].

We hypothesized that the area affected by temporal bone fractures may influence audiometric changes, particularly the conductive component of hearing loss in the otic capsule preserving temporal bone fracture. The areas affected by temporal bone fracture were divided into the ossicular chain and three temporal bone subsites (i.e., the external auditory canal [EAC], middle ear [ME], and mastoid [M]). Based on this categorization system, we reviewed the temporal bone computed tomography (TBCT) and audiograms of otic capsule-preserving temporal bone fracture patients, to evaluate the relationship between the temporal bone subsite involved and initial and improved airbone $(\mathrm{AB})$ gap values.

\section{MATERIALS AND METHODS}

\section{Ethical considerations}

This study was approved by the Institutional Review Board of the Boramae Medical Center, Seoul Metropolitan GovernmentSeoul National University (IRB No. 26-2014-82).

\section{Study participants}

A retrospective study design and data gathered between January 2004 and January 2014 were used. All of the included patients visited the otolaryngology clinics of Seoul National University Hospital or Boramae Medical Center, Seoul Metropolitan Government-Seoul National University with a temporal bone fracture; their medical records were retrospectively reviewed. Patients who had otic capsule-violating temporal bone fractures; petrous bone involvement; hearing impairment in the contralateral ear; did not undergo TBCT or audiogram; had $>1$ week of the time interval between their initial audiogram and TBCT; or underwent surgical treatment for hearing recovery, such as ossiculoplasty or mastoidectomy, were excluded. All of the patients underwent TBCT an average of 9.5 days (range, 0 to 37 days) after temporal bone fracture, with initial audiometry performed an average of 7.1 days (range, 0 to 36 days) after temporal bone fracture.

\section{H I G H L I G H T S}

- The temporal bone area fractured is associated with severity and course of conductive hearing loss.

- Air-bone (AB) gap was highly improved in cases with external auditory canal, middle ear, and mastoid fractured.

- AB-gap was least improved at 2,000 Hz.

\section{Audiometric evaluation}

All of the enrolled patients underwent audiologic evaluation within 1 week of TBCT. Hearing levels were determined by pure tone audiometry. We performed serial audiograms to detect any noticeable changes in hearing $>30$ days after the initial audiogram. All of the initial audiograms were conducted in Boramae Medical Center, Seoul Metropolitan GovernmentSeoul National University, and pure tone thresholds for air conduction (AC) and bone conduction (BC) were recorded at 250, $500,1,000,2,000$, and $4,000 \mathrm{~Hz}$ for each ear, and reported as decibels of hearing loss (dB HL). Then, $A B$ gap improvement (initial $\mathrm{AB}$ gap-final $\mathrm{AB}$ gap) values were calculated at 250, 500, $1,000,2,000$, and $4,000 \mathrm{~Hz}$ on the ipsilateral side of the temporal bone fracture. The pure tone average across the frequencies was calculated in accordance with the four-tone average value $(250,500,1,000,2,000$, and 4,000 Hz).

\section{Classification of temporal bone subsite involvement}

Non-contrast-enhanced, high-resolution, multi-slice CT examination of the temporal bone was performed at Boramae medical center, Seoul metropolitan Government-Seoul National university. On axial slices, the involvement or noninvolvement of the three parts of the temporal bone (EAC, ME, and M), and ossicular chain $(\mathrm{O})$ fracture or dislocation, were evaluated; involvement of a given part was denoted by a definite fracture line or haziness in the TBCT. Fractures involving the otic capsule were defined as those exhibiting labyrinth, cochlea, vestibule, or semicircular canal fracture or dislocation; all such fractures were excluded.

\section{Statistical analysis}

The IBM SPSS ver. 21.0 (IBM Co., Armonk, NY, USA) software package was used for the analyses. The Mann-Whitney $U$-test was used to compare the pure tone thresholds of each group. To elucidate the relationship between temporal bone subsite involvement and the $\mathrm{AB}$ gap, univariate analysis was performed using $t$-tests. Multiple linear regression analyses were then conducted. A $P$-value $<0.05$ indicated statistical significance.

\section{RESULTS}

A total of 97 patients satisfied the inclusion criteria, of whom 71 underwent follow-up audiogram $>30$ days after their initial audiogram. The patients' mean age was $41.6 \pm 23.9$ years, and the sex ratio (male/female) was 2:1. According to the involved subsites of temporal bone fracture, the initial $\mathrm{AB}$ gaps were significant different in $\mathrm{O}$ and $\mathrm{ME}$ at $250 \mathrm{~Hz} / \mathrm{M}$ at $500 \mathrm{~Hz} / \mathrm{O}$ and $\mathrm{M}$ at $1 \mathrm{kHz} / \mathrm{O}$ at $2 \mathrm{kHz} / \mathrm{O}$ and $\mathrm{M}$ at $4 \mathrm{kHz}$, respectively (Table 1). The improvement of $\mathrm{AB}$ gap was also showed significant differences in $\mathrm{M}$ at $500 \mathrm{~Hz}(P=0.04)$ (Table 2).

To evaluate the relations between the $\mathrm{AB}$ gap and the detailed 
Table 1. The initial air-bone (AB) gap of each frequency according to the involved subsites

\begin{tabular}{|c|c|c|c|}
\hline \multirow{2}{*}{ Frequency } & \multicolumn{2}{|c|}{ Initial AB gap } & \multirow{2}{*}{$P$-value } \\
\hline & Involved & Not-involved & \\
\hline \multicolumn{4}{|l|}{$250 \mathrm{~Hz}$} \\
\hline Ossicle & $36.0 \pm 20.4$ & $22.3 \pm 19.3$ & $0.001^{*}$ \\
\hline Mastoid & $30.4 \pm 20.3$ & $24.4 \pm 21.4$ & 0.172 \\
\hline Middle ear & $33.8 \pm 21.6$ & $23.3 \pm 18.8$ & $0.013^{*}$ \\
\hline External auditory canal & $29.6 \pm 21.0$ & $22.5 \pm 18.4$ & 0.238 \\
\hline \multicolumn{4}{|l|}{$500 \mathrm{~Hz}$} \\
\hline Ossicle & $29.8 \pm 20.5$ & $20.5 \pm 18.8$ & 0.166 \\
\hline Mastoid & $27.5 \pm 18.4$ & $19.4 \pm 19.2$ & $0.042^{*}$ \\
\hline Middle ear & $28.1 \pm 19.9$ & $21.4 \pm 17.7$ & 0.076 \\
\hline External auditory canal & $25.4 \pm 18.8$ & $21.8 \pm 19.9$ & 0.512 \\
\hline \multicolumn{4}{|l|}{$1 \mathrm{kHz}$} \\
\hline Ossicle & $28.8 \pm 20.7$ & $20.7 \pm 17.5$ & $0.020^{*}$ \\
\hline Mastoid & $27.3 \pm 17.3$ & $19.1 \pm 17.1$ & $0.031^{*}$ \\
\hline Middle ear & $27.4 \pm 17.7$ & $21.6 \pm 17.3$ & 0.110 \\
\hline External auditory canal & $25.4 \pm 17.3$ & $20.4 \pm 18.8$ & 0.324 \\
\hline \multicolumn{4}{|l|}{$2 \mathrm{kHz}$} \\
\hline Ossicle & $18.7 \pm 14.0$ & $12.0 \pm 13.9$ & $0.020^{*}$ \\
\hline Mastoid & $15.9 \pm 14.6$ & $13.5 \pm 14.2$ & 0.451 \\
\hline Middle ear & $17.4 \pm 16.5$ & $12.9 \pm 12.0$ & 0.132 \\
\hline External auditory canal & $15.4 \pm 14.9$ & $14.3 \pm 11.2$ & 0.801 \\
\hline \multicolumn{4}{|l|}{$4 \mathrm{kHz}$} \\
\hline Ossicle & $30.1 \pm 20.4$ & $17.1 \pm 17.6$ & $0.001^{*}$ \\
\hline Mastoid & $25.4 \pm 19.9$ & $17.4 \pm 18.5$ & $0.051^{*}$ \\
\hline Middle ear & $26.4 \pm 22.9$ & $18.9 \pm 15.5$ & 0.064 \\
\hline External auditory canal & $23.4 \pm 20.4$ & $18.9 \pm 15.1$ & 0.431 \\
\hline
\end{tabular}

*Significance at $P<0.05$.

involved subsites, these patients were divided into 12 groups according to their temporal bone involvement areas (M, ME, EAC, and O) (Supplementary Table 1). Because outliers were possible in certain instances, groups with more than six patients were further analyzed with respect to audiologic patterns according to the detailed involvements of subsites. Audiometric changes associated with both the initial and improved $A B$ gap values were analyzed in four groups with no ossicular chain involvement $(\mathrm{M}, \mathrm{ME}+\mathrm{M}, \mathrm{EAC}+\mathrm{M}$, and $\mathrm{EAC}+\mathrm{ME}+\mathrm{M})$, and in two groups with ossicular chain involvement $(\mathrm{O}+\mathrm{ME}+\mathrm{M}, \mathrm{O}+\mathrm{EAC}+$ $\mathrm{ME}+\mathrm{M})$.

The initial $\mathrm{AB}$ gap was smallest in the M group (mean gap, 9.2 $\mathrm{dB}$ HL) (Fig. 1). The mean AB gaps of the ME+M, EAC+M, and $\mathrm{EAC}+\mathrm{ME}+\mathrm{M}$ groups were $15.9 \mathrm{~dB} \mathrm{HL}, 15.8 \mathrm{~dB} \mathrm{HL}$, and 18.2 $\mathrm{dB} H \mathrm{HL}$, respectively. The ossicular chain involvement groups exhibited larger initial $\mathrm{AB}$ gaps compared to the equivalent nonossicular chain involvement groups. In particular, significantly larger initial $\mathrm{AB}$ gaps were observed in the ossicular chain involvement groups at 1,000 and $2,000 \mathrm{~Hz}(P=0.020$ at both 1,000 and $2,000 \mathrm{~Hz}, \mathrm{EAC}+\mathrm{ME}+\mathrm{M}$ vs. $\mathrm{O}+\mathrm{EAC}+\mathrm{ME}+\mathrm{M}$ group). Concerning the ossicular chain involvement groups, the $\mathrm{O}+\mathrm{EAC}+\mathrm{ME}+\mathrm{M}$ group exhibited a larger initial AB gap com-
Table 2. The improvement of air-bone (AB) gap of each frequency according to the involved subsites

\begin{tabular}{|c|c|c|c|}
\hline \multirow{2}{*}{ Frequency } & \multicolumn{2}{|c|}{ Improvement of $A B$ gap } & \multirow{2}{*}{$P$-value } \\
\hline & Involved & Not-involved & \\
\hline \multicolumn{4}{|l|}{$250 \mathrm{~Hz}$} \\
\hline Ossicle & $24.6 \pm 20.5$ & $18.1 \pm 17.3$ & 0.152 \\
\hline Mastoid & $23.9 \pm 17.8$ & $16.0 \pm 19.9$ & 0.091 \\
\hline Middle ear & $26.4 \pm 22.9$ & $18.9 \pm 19.2$ & 0.340 \\
\hline External auditory canal & $20.8 \pm 19.2$ & $26.3 \pm 16.2$ & 0.444 \\
\hline \multicolumn{4}{|l|}{$500 \mathrm{~Hz}$} \\
\hline Ossicle & $20.6 \pm 22.9$ & $19.1 \pm 17.0$ & 0.751 \\
\hline Mastoid & $23.2 \pm 20.1$ & $13.5 \pm 17.8$ & $0.040^{*}$ \\
\hline Middle ear & $20.0 \pm 18.3$ & $19.6 \pm 21.8$ & 0.921 \\
\hline External auditory canal & $19.1 \pm 19.8$ & $27.5 \pm 18.5$ & 0.262 \\
\hline \multicolumn{4}{|l|}{$1 \mathrm{kHz}$} \\
\hline Ossicle & $17.8 \pm 18.5$ & $17.9 \pm 15.6$ & 0.984 \\
\hline Mastoid & $20.7 \pm 17.2$ & $12.9 \pm 15.0$ & 0.061 \\
\hline Middle ear & $18.7 \pm 15.3$ & $17.1 \pm 18.9$ & 0.693 \\
\hline External auditory canal & $18.3 \pm 16.7$ & $25.0 \pm 16.7$ & 0.231 \\
\hline \multicolumn{4}{|l|}{$2 \mathrm{kHz}$} \\
\hline Ossicle & $14.0 \pm 15.9$ & $10.6 \pm 13.9$ & 0.344 \\
\hline Mastoid & $13.3 \pm 15.2$ & $9.9 \pm 14.3$ & 0.361 \\
\hline Middle ear & $13.2 \pm 16.9$ & $10.9 \pm 12.4$ & 0.531 \\
\hline External auditory canal & $11.8 \pm 15.3$ & $16.3 \pm 10.6$ & 0.430 \\
\hline \multicolumn{4}{|l|}{$4 \mathrm{kHz}$} \\
\hline Ossicle & $15.6 \pm 21.4$ & $14.0 \pm 17.6$ & 0.740 \\
\hline Mastoid & $15.3 \pm 20.8$ & $11.9 \pm 18.4$ & 0.500 \\
\hline Middle ear & $14.4 \pm 23.4$ & $10.9 \pm 12.4$ & 0.892 \\
\hline External auditory canal & $13.8 \pm 20.9$ & $18.1 \pm 11.6$ & 0.571 \\
\hline
\end{tabular}

*Significance at $P<0.05$.

pared to the $\mathrm{O}+\mathrm{ME}+\mathrm{M}$ group $(33.4$ and $26.1 \mathrm{~dB} \mathrm{HL}$, respectively). The $\mathrm{M}$ group had the smallest initial $\mathrm{AB}$ gap on pure tone audiometry, aside from at $2,000 \mathrm{~Hz}$ (Fig. 1). More specifically, at lower tones $(250,500$, and $1,000 \mathrm{~Hz})$ the $\mathrm{AB}$ gap was significantly larger in the $\mathrm{ME}+\mathrm{M}, \mathrm{EAC}+\mathrm{M}$, and $\mathrm{EAC}+\mathrm{ME}+\mathrm{M}$ groups compared to the $\mathrm{M}$ group $(P=0.051, P=0.050$, and $P=0.020$, for 250,500 , and $1,000 \mathrm{~Hz}$, respectively). Moreover, the initial $\mathrm{AB}$ gaps at 250 and $500 \mathrm{~Hz}$ were larger in the $\mathrm{EAC}+\mathrm{ME}+\mathrm{M}$ group compared to the $\mathrm{ME}+\mathrm{M}$ or $\mathrm{EAC}+\mathrm{M}$ group, although the difference was not significant. The initial $\mathrm{AB}$ gaps in the $\mathrm{ME}+\mathrm{M}$ and $\mathrm{EAC}+\mathrm{M}$ groups were similar.

$\mathrm{AB}$ gap improvement was smallest in the $\mathrm{M}$ group (mean $\mathrm{AB}$ gap improvement, $7.3 \mathrm{~dB}$ HL) (Fig. 2) and largest in the $\mathrm{EAC}+\mathrm{ME}+\mathrm{M}$ (mean improvement, 17.3 dB HL), followed by the $\mathrm{ME}+\mathrm{M}$ group (mean improvement, $15.1 \mathrm{~dB} \mathrm{HL}$ ) and $\mathrm{EAC}+\mathrm{M}$ group (mean improvement, $10.5 \mathrm{~dB} \mathrm{HL}$ ); these differences were not significant. Concerning the ossicular chain involvement groups, the $\mathrm{O}+\mathrm{EAC}+\mathrm{ME}+\mathrm{M}$ group exhibited greater $\mathrm{AB}$ gap improvement compared to the $\mathrm{O}+\mathrm{ME}+\mathrm{M}$ group $(21.2$ $\mathrm{dB} \mathrm{HL}$ and $16.9 \mathrm{~dB} \mathrm{HL}$, respectively), although this difference was not significant. AB gap improvement was smallest at 2,000 $\mathrm{Hz}$ in all of the groups. Considering the differences of the initial 

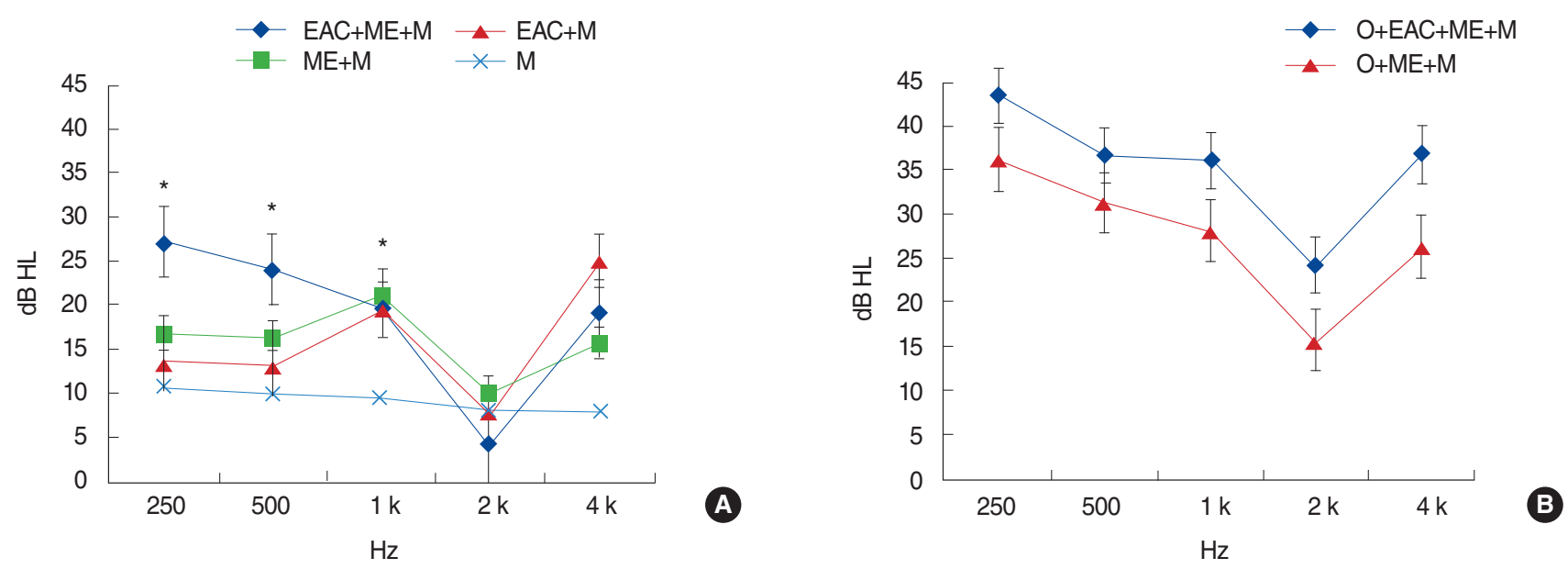

Fig. 1. Initial air-bone gap according to involvement range of temporal bone. (A) Patients with intact ossicular chain. (B) Patients with ossicular chain disruption or dislocation. EAC, external auditory canal; ME, middle ear; $M$, mastoid; $\mathrm{O}$, ossicle. ${ }^{\star} P<0.05$.
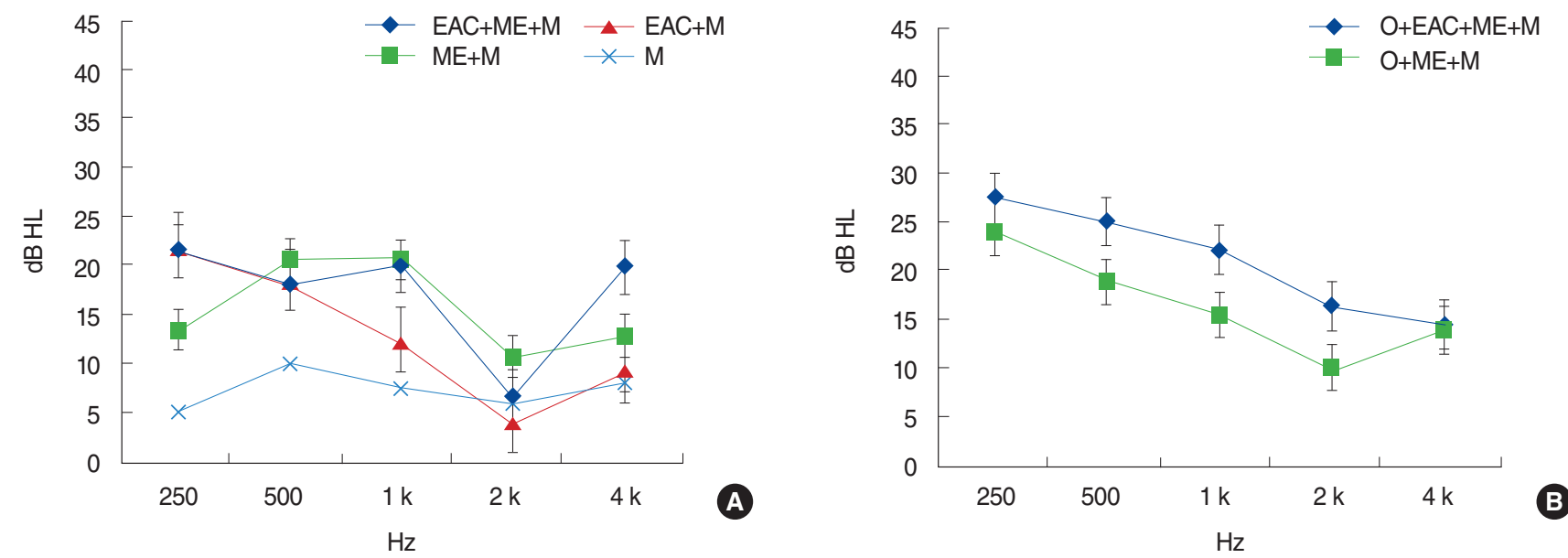

Fig. 2. Improvement of air-bone gap (initial air-bone gap-final air-bone gap) according to involvement range of temporal bone. (A) Patients with intact ossicular chain. (B) Patients with ossicular chain disruption or dislocation. EAC, external auditory canal; ME, middle ear; M, mastoid; $\mathrm{O}$, ossicle. ${ }^{*} P<0.05$

$A B$ gaps, we also analyzed the differences of the $A B$ gap improvement ratio ( $\mathrm{AB}$ gap improvement/ initial $\mathrm{AB}$ gap), which showed no significant difference between groups.

Changes between initial and improved $\mathrm{AB}$ gap values were analyzed during univariate, followed by multivariate analysis, in accordance with the temporal bone subsites involved. Ossicular chain involvement significantly influenced the initial $\mathrm{AB}$ gap value at 250,1,000, 2,000, and 4,000 $\mathrm{Hz}$ following adjustment for the involvement of temporal bone subsites (M, ME, and EAC; $P=0.001, P=0.022, P=0.021$, and $P=0.001$, respectively). ME involvement differed significantly between groups with respect to the initial $\mathrm{AB}$ gap at $250 \mathrm{~Hz}$, as did $\mathrm{M}$ involvement for the initial $A B$ gap at $500,1,000$, and $4,000 \mathrm{~Hz}$ (on univariate analysis; this significance was lost on multivariate analysis). $A B$ gap improvement did not differ between groups for any other subsite.

\section{DISCUSSION}

There are several complications associated with temporal bone fracture, including hearing loss, facial nerve paralysis [10], and cerebrospinal fluid otorrhea [1]; hearing loss is among the most commonly encountered symptoms of temporal bone fracture [11].

Several previous studies have demonstrated associations between different types of hearing loss and temporal bone fracture $[4,6,7]$. For example, transverse fracture results in more SNHL compared to $\mathrm{CHL}$, whereas longitudinal fracture causes more CHL than SNHL. Otic capsule-violating and petrous bone-involving fractures tend to cause SNHL $[4,6,7]$. Furthermore, one report indicated that ME involvement in nonpetrous fracture exhibits a 4-fold stronger correlation with CHL than the traditional classification system (i.e., longitudinal, transverse, or mixed) [4]. 
However, transverse, otic capsule-violating, and petrous bone fractures only comprise a very small proportion of all temporal bone fractures $[9,12]$. The majority of temporal bone fracture cases that we have encountered are otic capsule-preserving and nonpetrous bone fractures. However, until now, there was no classification method for the prediction of hearing outcomes during otic capsule-preserving temporal bone fracture.

Our data indicate that the specific temporal bone area involved can predict the degree of CHL. To predict $\mathrm{AB}$ gap values, we assessed lesion haziness in the TBCT due either to mucosal swelling, hemorrhage or hematoma, in addition to the fracture line. These parameters exhibited good correlations with initial $\mathrm{AB}$ gap values, particularly at lower tones. Fluid accumulating in the ME, caused by hematoma or effusion, is frequently associated with 20-30 dB CHL [13]. At lower frequencies, the primary mechanism underlying hearing loss is reduced admittance in the middle-ear air space, due to air displacement by fluid. At higher frequencies, the primary mechanism underlying hearing loss is increased tympanic membrane mass due to entrained fluid. Fluid viscosity had no significant effect on umbo velocity [13]. The AB gap was smallest at 2,000 Hz, which reflects the influence of ME pathology (involving an intact ossicular chain) on low-tone AC thresholds.

The extent of $\mathrm{AB}$ gap improvement depended on the range of the involved area; this can be explained by the absorption of hematoma, which reduces mucosal swelling. In fact, $\mathrm{AB}$ gap improvement was largest in those groups characterized by EAC and ME involvement (Fig. 2). An additive effect of EAC and ME involvement on $\mathrm{AB}$ gap improvement was not observed, although there was a tendency towards greater $A B$ gap improvement in the context of EAC and ME involvement (Fig. 2). The initial AB gap in the ossicular chain involvement groups was larger compared to the corresponding no-O involvement groups, particularly at 2,000 Hz; this reflects the influence of ossicular chain defects (Fig. 1). However, changes in the AB gap were comparable between the ossicular chain involvement and no-involvement groups (Fig. 2), because hearing loss caused by ossicular disruption or dislocation had not been restored, whereas hematoma resorption or mucosal swelling subsidence occurred in both groups.

There were some limitations in the present study. There was variability with respect to the time at which temporal bone fracture occurred, and the time at which patients underwent TBCT or audiogram, which could have affected the correlation between temporal bone fracture site and audiogram (Table 1). However, this was unavoidable because patients with temporal bone fracture occasionally cannot undergo TBCT or audiogram, or experience other critical medical problems such as brain hemorrhage or fatal multiple fracture prior to temporal bone fracture evaluation. To minimize these limitations, we excluded data from patients who underwent TBCT $>36$ days, and audiogram $>37$ days, after sustaining their temporal bone fracture.
Moreover, the time interval between TBCT and the initial audiogram was also limited to 7 days; therefore, it can be inferred that the initial audiogram reflected the temporal bone condition observed on TBCT. Due to the small sample size, not all of the subsites were characterized by significant group differences. Future studies using larger samples are warranted to quantify the contribution of particular subsites to CHL.

In conclusion, CHL after otic capsule-preserving temporal bone fracture varied in accordance with the temporal bone area involved. Hematoma absorption and mucosal swelling subsidence in temporal bone subsites may result in $\mathrm{AB}$ gap and $\mathrm{AC}$ threshold improvements. The associations between audiometric change and EAC, ME, and M involvement should be validated in future studies, which will allow for a more accurate prediction of the degree of hearing loss in, and the prognosis of, temporal bone fracture patients.

\section{CONFLICT OF INTEREST}

No potential conflict of interest relevant to this article was reported.

\section{REFERENCES}

1. Johnson F, Semaan MT, Megerian CA.Temporal bone fracture: evaluation and management in the modern era. Otolaryngol Clin North Am. 2008 Jun;41(3):597-618.

2. Nicol JW, Johnstone AJ. Temporal bone fractures in children: a review of 34 cases. J Accid Emerg Med. 1994 Dec;11(4):218-22.

3. Wysocki J. Cadaveric dissections based on observations of injuries to the temporal bone structures following head trauma. Skull Base. 2005 May;15(2):99-106.

4. Ishman SL, Friedland DR. Temporal bone fractures: traditional classification and clinical relevance. Laryngoscope. 2004 Oct;114(10): 1734-41.

5. Dahiya R, Keller JD, Litofsky NS, Bankey PE, Bonassar LJ, Megerian CA. Temporal bone fractures: otic capsule sparing versus otic capsule violating clinical and radiographic considerations. J Trauma. 1999 Dec;47(6):1079-83.

6. Kang HM, Kim MG, Boo SH, Kim KH, Yeo EK, Lee SK, et al. Comparison of the clinical relevance of traditional and new classification systems of temporal bone fractures. Eur Arch Otorhinolaryngol. 2012 Aug;269(8):1893-9.

7. Little SC, Kesser BW. Radiographic classification of temporal bone fractures: clinical predictability using a new system. Arch Otolaryngol Head Neck Surg. 2006 Dec;132(12):1300-4.

8. Rafferty MA, Mc Conn Walsh R, Walsh MA. A comparison of temporal bone fracture classification systems. Clin Otolaryngol. 2006 Aug;31(4):287-91.

9. Sun GH, Shoman NM, Samy RN, Cornelius RS, Koch BL, Pensak ML. Do contemporary temporal bone fracture classification systems reflect concurrent intracranial and cervical spine injuries? Laryngoscope. 2011 May;121(5):929-32.

10. Montava M, Mancini J, Masson C, Collin M, Chaumoitre K, Lavieille JP.Temporal bone fractures: sequelae and their impact on quality of life.Am J Otolaryngol. 2015 May-Jun;36(3):364-70. 
11. Yetiser S, HidirY, Gonul E. Facial nerve problems and hearing loss in patients with temporal bone fractures: demographic data. J Trauma. 2008 Dec;65(6):1314-20.

12. Blake DM, Tomovic S, Jyung RW.Temporal bone fracture. Ear Nose
Throat J. 2014 Jan;93(1):16-25.

13. Ravicz ME, Rosowski JJ, Merchant SN. Mechanisms of hearing loss resulting from middle-ear fluid. Hear Res. 2004 Sep;195(1-2):10330. 
Supplementary Table 1. Classifications and incidences of temporal bone fracture according to range of involvement area of temporal bone

\begin{tabular}{lrr}
\hline Temporal bone subsite & Initial audio & Follow-up audio \\
\hline Involved subsite & & \\
M & $83(85.6)$ & $64(90.1)$ \\
ME & $63(65.0)$ & $47(66.2)$ \\
EAC & $48(49.5)$ & $39(55.0)$ \\
O & $41(42.3)$ & $38(53.5)$ \\
Detailed involved subsite & & \\
M & $10^{\text {a) }}(10.3)$ & $10^{\text {a) }}(14.1)$ \\
ME & $3(3.1)$ & $1(1.4)$ \\
EAC & $4(4.1)$ & $1(1.4)$ \\
M+ME & $16^{\text {a) }}(16.5)$ & $7^{\text {a) }}(9.9)$ \\
M+EAC & $11^{\text {a) }}(11.3)$ & $9^{\text {a) }}(12.7)$ \\
ME+EAC & $1(1.0)$ & $1(1.4)$ \\
M+ME+EAC & $6^{\text {a) }}(6.2)$ & $4^{\text {a) }}(5.6)$ \\
O+M & $1(1.0)$ & $1(1.4)$ \\
O+ME & $2(2.1)$ & 0 \\
O+M+ME & $17^{\text {a) }}(17.5)$ & $14^{\text {a) }}(19.7)$ \\
O+M+EAC & $3(3.1)$ & $3(4.2)$ \\
O+M+ME+EAC & $23^{\text {a) }}(23.7)$ & $20^{\text {a) }}(28.2)$ \\
Total & $97(100.0)$ & $71(100.0)$ \\
\hline
\end{tabular}

Values are presented as number (\%).

M, mastoid; ME, middle ear; EAC, external auditory canal; O, ossicles.

a) Groups performed further analysis on the audiologic evaluations. 